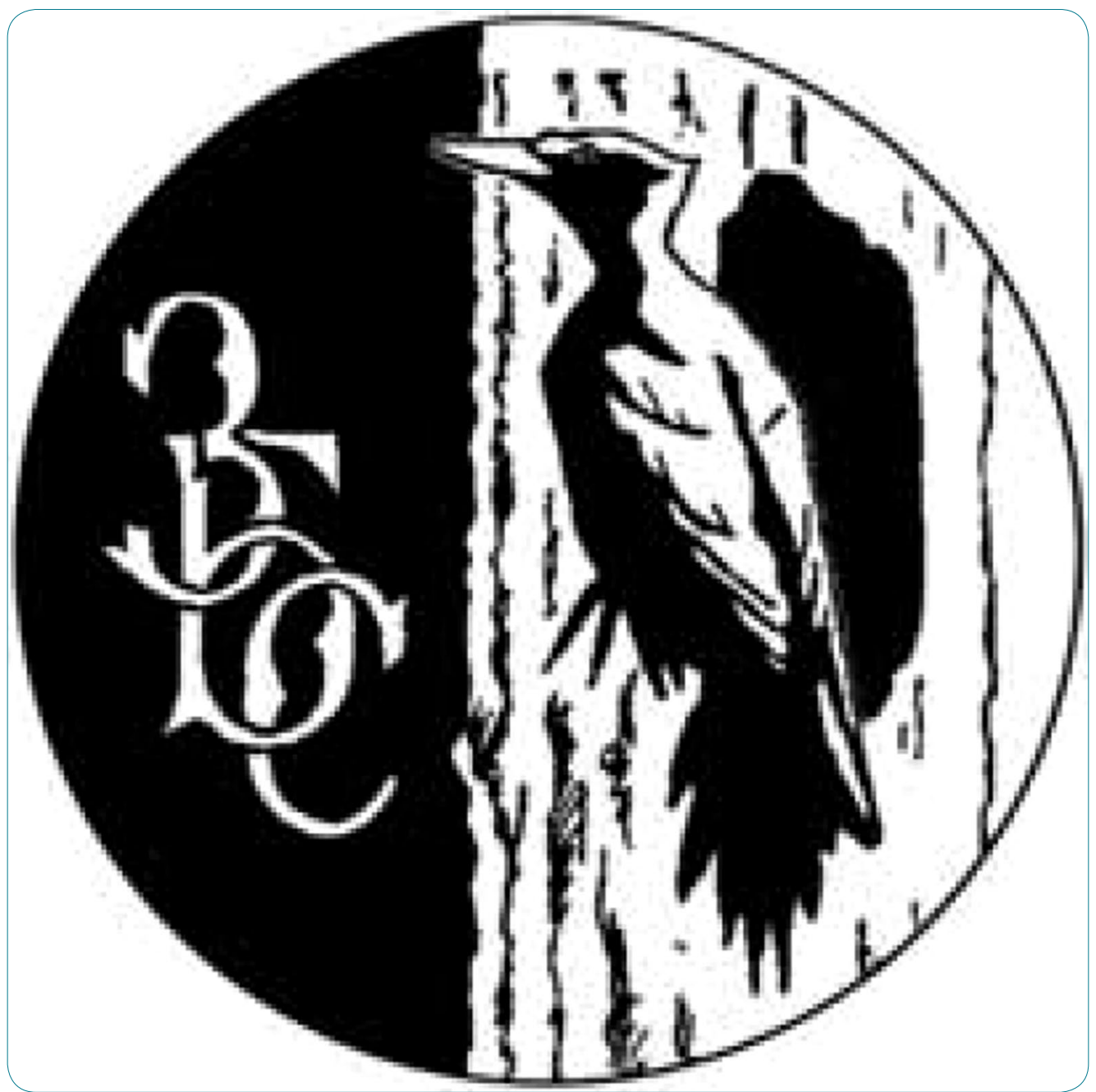

The stoichiometric approach in determining total evaporative water loss and the relationship between evaporative and non-evaporative heat loss in two resting bird species: passerine and non-passerine

Gavrilov 


\title{
The stoichiometric approach
} in determining total evaporative water loss and the relationship between evaporative and non-evaporative heat loss in two resting bird species: passerine and non-passerine

Valery M. Gavrilov*

\begin{abstract}
Background: Evaporation is of significant ecological interest. Evaporation from an animal always results in a decrease in the temperature of the surface from which the evaporation occurs. Therefore, evaporation is a one-way transfer which causes heat loss from the organism. Biological evaporation always involves the loss of water which is a vital resource for nearly all biochemical processes. Evaporation is loss of heat via loss of body mass.

Methods: The simultaneous determination of energy expenditure and loss of body mass in resting birds allows us to estimate evaporative heat loss. This method includes direct measurements of the energetic equivalent of the loss of body mass as the ratio between heat production, determined by the rate of oxygen consumption and the loss of body mass at various ambient temperatures.

Results: The data indicate that evaporation was minimal at lower critical temperature and that the rate of evaporation increased at lower or higher temperatures. Obtained results indicate that passerine and non-passerine species have the ability to change their non-evaporative heat conductance the same number of times (approximately fourfold), and that their abilities in this respect are similar.

Conclusions: The novelty of the study resides in the stoichiometric approach to determination of total evaporative water loss. The analysis shows that determinations by stoichiometric approach of total evaporative water loss yielded the values, which fit into the confidence intervals of all equations from literatures. The basal metabolic rate and nonevaporative thermal conductance are fundamental parameters of energetics and determine the level of physiological organization of an endothermic animal.
\end{abstract}

Keywords: Water loss, Heat dissipation, Evaporation, Respiration, Chloris chloris, Melopsittacus undulatus, Thermoregulation, Metabolic rate, Stoichiometry

\section{Background}

Birds change their thermal conductance in various ways. This is attained by changing the plumage position (compressing or ruffling) as well as by changing the blood inflow to the skin, which varies according to the needs

*Correspondence: vmgavrilov@mail.ru

Department of Vertebrate Zoology and Skadovsky Zvenigorod Biological

Station, Lomonosov Moscow State University, Moscow 119991, Russia of thermoregulation (vasomotor responses). Under cold stress, the skin vessels contract and the blood flow through the skin is minimal; however, when it is necessary to increase the heat loss due to a high temperature or increased activity, the blood flow through the skin increases considerably [1-4].

Birds are endothermic animals and possess the following characteristics, a relatively high and constant body temperature, which coincides with the maximum 
of the Boltzmann distribution of molecular energy, heat insulating covers, ability to change heat loss and metabolism that cannot fall below a minimal value in a state of rest, which is called the basal metabolic rate (BMR). Endothermic animals can change their thermal conductance properties over a wide range. In birds, this change is attained by changing the plumage position (pressing or ruffling) and the influx of blood to the skin, which varies according to the demands of thermoregulation (vasomotor reactions). At low temperatures, the blood vessels constrict, which results in minimal blood flow through the skin; however, when heat loss increases because of high ambient temperature $\left(T_{\mathrm{A}}\right)$, the blood flow through the skin significantly increases [5-9]. Thermal conductance in the context of this study is the measure of heat flow from the animal into the environment. This heat flow includes the transfer of heat from the internal parts of the body to the skin surface and from the skin surface through the feather cover into the environment. Low thermal conductance connotes high thermo-insulating properties, and high thermal conductance connotes low thermoinsulating properties. In essence, thermal conductance is a property that is opposite to heat insulation. Therefore, there are many methods of conductance in endothermic animals, depending on the degree of insulation, which varies at rest from the minimum (at low ambient temperatures when insulation is maximum, $h_{1}$, with evaporation, $h_{\text {min }}$, non-evaporative) to the maximum (at high ambient temperatures when insulation is minimal $h_{\mathrm{u}}$, with evaporation, $h_{\max }$, non-evaporative).

The ways of non-evaporative and evaporative conductance explains the existence of thermoneutral zone, which is the range of ambient temperatures in which minimal metabolism (basal metabolic rate, BMR) can be maintained at a constant level. The thermoneutral range is a phenomenon intrinsic only in endothermic animals. The existence of a thermoneutral range is not in accordance with physical models. It is formed as a result of the following independent properties of endothermic animals: (1) They have body covers that can change the thermal conductance from minimal to maximal; (2) The presence of vasomotor reactions capable of regulating blood flow to suit the requirements of thermal regulation; and (3) The inability for animals to decrease heat production below the level that determines the rate of basic physiological processes.

Endothermic animals exchange heat with the environment via four modes: conduction, convection, radiation and evaporation [10]. Evaporation is of significant ecological interest. Evaporation from an animal always results in a decrease in the temperature of the surface from which the evaporation occurs. Therefore, evaporation is a one-way transfer which causes heat loss from the organism. Biological evaporation always involves the loss of water which is a vital resource for nearly all biochemical processes. Evaporation is loss of heat via loss of body mass. Experimental determination of total evaporation has been performed for many species of birds using various methods and terms to describe the evaporative routes (e.g., [11-17].

Total evaporative water loss (TEWL) at ambient temperature $25^{\circ} \mathrm{C}$ is summarized in two reviews $[18,19]$. The chief mechanisms for the transition of minimal to maximal heat loss are a change in plumage position, from ruffled to tightly pressed, the change in blood flow as a result of vasomotor reactions and adaptive rate of evaporation [2-4].

First guidance for the direct weighing method for determines evaporative water loss was obtained from the studies of Hutchinson and Sykes [20] and Hutchinson [21, 22] on evaporation in the domestic fowl. Lasiewski et al. [15] using new techniques and equipments invented new methods different from the original method. A major disadvantage of the direct weighing method is that it does not permit the simultaneous determination of the energetic cost of evaporative cooling by monitoring oxygen consumption or carbon dioxide production, as is possible in the open flow method. My method is based on the law of conservation of mass where the total mass of the reactants equals the total mass of the products leading to the insight that the relations among quantities of reactants and products typically form a ratio of positive integers (stoichiometry). The method uses the metabolic rate (oxygen consumption) of the bird at different ambient temperature $\left(T_{\mathrm{A}}\right)$, respiratory quotient $(\mathrm{RQ})$, the loss of body mass and the energetic equivalent of the loss of body mass $(q)$ as the ratio between heat production and the loss of body mass at various ambient temperatures $\left(T_{\mathrm{A}}\right)$. It is known that mass loss in a bird exposed to controlled conditions is due to three major factors [15]: (a) gaseous exchange-any excess of the weight of $\mathrm{CO}_{2}$ produced over the weight of $\mathrm{O}_{2}$ consumed, (b) fecal and urinary loss, and (c) evaporative water loss. When the metabolic responses of the bird and RQ are known, one can easily account for total evaporative water loss.

The following questions are discussed in this paper: (1) How do the TEWL measurements based on the energy equivalent of the body mass loss $(q)$ compare to the TEWL values obtained by the open flow method? (2) Then, based on data on the metabolic rate of birds, how data on TEWL can be used to determine the ratio between evaporative and non-evaporative heat loss in birds at different ambient temperatures? 


\section{Methods}

The study was performed in Moscow Region at Zvenigorod Biological Station $\left(55^{\circ} 44^{\prime} \mathrm{N}, 36^{\circ} 51^{\prime} \mathrm{E}\right)$. Two common species-one of passerine, European Greenfinch (Chloris chloris) and one of non-passerine, Budgerigar (Melopsittacus undulatus) birds with similar body masses were chosen for analysis.

All birds were maintained in large indoor aviaries at natural daylengths and temperatures for no less than 1 year. The aviaries were heated in the winter to maintain temperatures of $5-10{ }^{\circ} \mathrm{C}$. These conditions facilitate accurate assessments of seasonal acclimatization [23]. The energy values for non-molting birds were measured in the winter (November-January, February) and summer (late May-June, late August-September). Studies of seasonal variation in energy expenditure, both at rest and during performance, were conducted at experimentally controlled temperatures, where $T_{\mathrm{A}}$ was varied from $-20{ }^{\circ} \mathrm{C}$ to $+45^{\circ} \mathrm{C}$ to construct a thermal energy profile of each of the studied species.

\section{Measurements of body mass variations in birds}

The following experiments were performed for more precise ascertainment of the speed at which food passes through the ali-mentary canal, and the character of mass variation at night. Post-absorptive birds were permitted to equilibrate in the dark for at least $3-4 \mathrm{~h}$ at the desired $T_{\mathrm{A}}$ and humidity before measurements were made. All determinations were performed in darkened chambers to minimize the activities of the birds. Groups of five European greenfinch, or just greenfinch (Chloris chloris) and budgerigars (Melopsittacus undulatus) were placed immediately after the evening feeding in a light low cage with a net floor to facilitate droppings of excrements into a cuvette with liquid mineral oil, in which the excrement sank (to prevent evaporation of water). The cage and cuvette were connected to scale-levers, for the registration of mass variation at night.

\section{Metabolic rate measurements}

To improve the efficiency of determining the level of metabolism, I used three different methods of measurement of oxygen consumption and carbon dioxide exhaled. Oxygen consumption is determined using Kalabukhov's closed-loop respirometer system [24] with my modifications $[25,26]$ in all the birds and at all studied ambient temperatures. The apparatus operates on the following principle: oxygen is consumed by the bird and the expired carbon dioxide is immediately absorbed. The decrease in gas pressure causes oxygen to be drawn from the container into the bird chamber (Fig. 1). Then an equal amount of water flows from the burette into

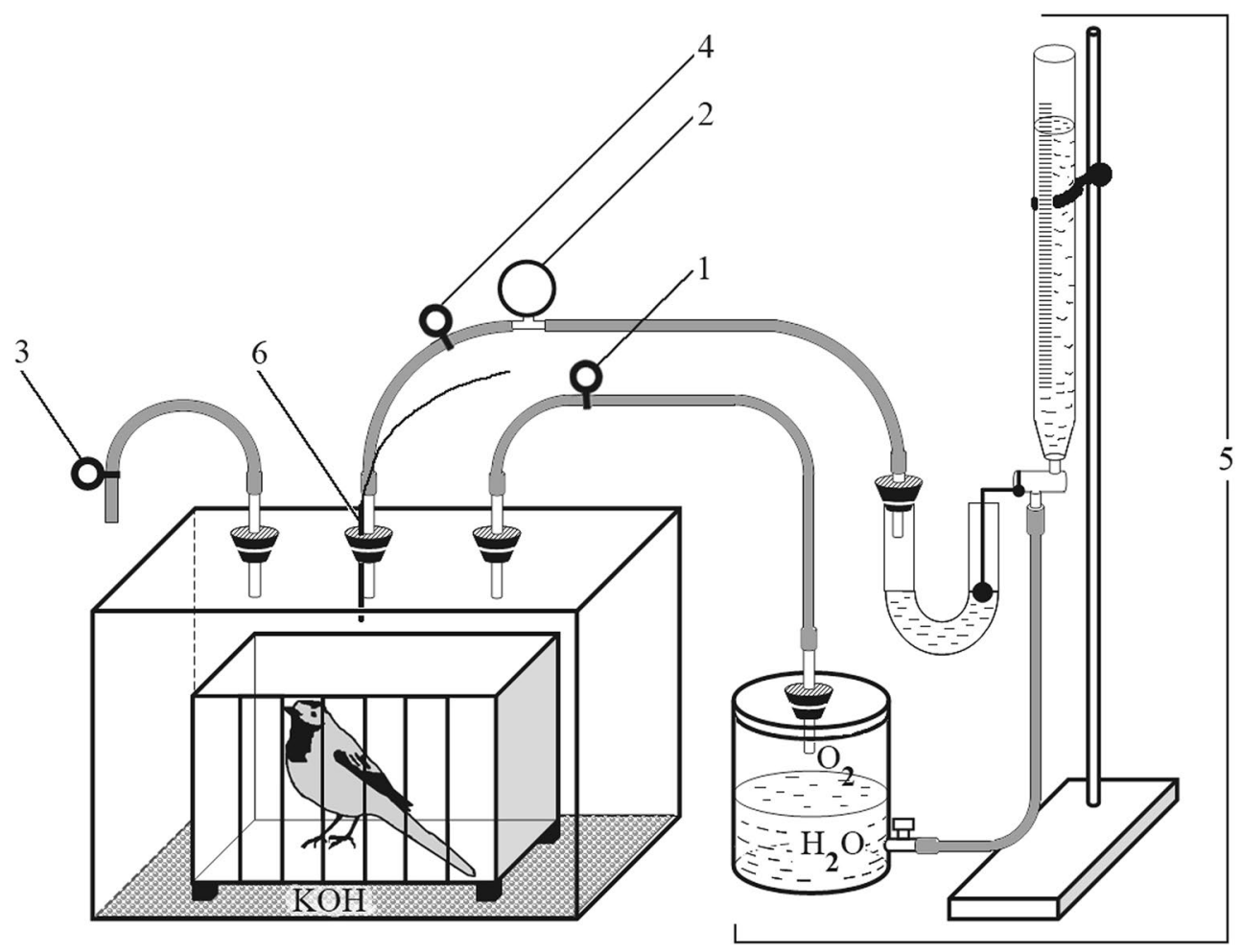

Fig. 1 Scheme of Kalabukhov respirometer with my modification. See text for explanations 
the container through the water-type pressure valve to replace the oxygen. Oxygen consumption can be read from the water level in the burette. During the experimental period the pressure inside the respirometer is slightly lower than the atmospheric pressure.

The birds were placed in a small cage with a wire mesh floor, which was subsequently placed in a sealed Plexiglas chambers in the dark. The chambers were connected to a ventilation pump [Fig. 1(2)], and the volume of a chamber was $4 \mathrm{~L}(250 \times 145 \times 110 \mathrm{~mm})$. After $2-3 \mathrm{~h}$, when the birds were asleep and the temperature in the chamber had stabilized, the chamber was connected to a device to measure the oxygen consumption [Fig. 1(5)]. The alkali $\mathrm{CO}_{2}$ absorbent $\mathrm{KOH}$ was placed in the chamber under the cage floor. The chambers were equipped with calibrated thermistors [Fig. 1(6)], and the temperature in the chamber was remotely monitored using an Electronik-16 potentiometer recorder (Electronschik, Russia). The chamber was placed in a thermostat or in the refrigerator. The measurements were obtained at no more than two temperatures for one night during the winter, and each measurement was obtained after acclimatization for 2-3 h. During the summer, the measurements were obtained at only one temperature because of short nights. The measurements were continuously obtained for $2-4 \mathrm{~h}$, and the data were recorded every hour. The accuracy of measurements was $\pm 0.1^{\circ} \mathrm{C}$ for temperature, $\pm 0.5 \mathrm{~mm} \mathrm{Hg}$ for atmospheric pressure and $\pm 0.2 \mathrm{~mL}$ for consumed oxygen volume. Measurements obtained using the respirometer were based on air pressure; therefore, they were sensitive to temperature changes. The data were not used when the temperature fluctuations with an hour in the sealed chamber exceeded $0.3^{\circ} \mathrm{C}$ for at least. The average volume of consumed oxygen, calculated while obtaining the metabolic rate measurements, was transformed into volume at standard temperature and pressure and converted to $\mathrm{kJ} /$ day according to the following equation: $1 \mathrm{~L}$ of $\mathrm{O}_{2}=15.97+5.16 \mathrm{RQ}(\mathrm{kJ})$ [27]. Thus, the oxygen consumption was measured at rest at different ambient temperatures $\left(-20^{\circ} \mathrm{C}\right.$ to $\left.+45^{\circ} \mathrm{C}\right)$.

After measuring the metabolic rate (MR), the birds were weighed to the nearest $0.1 \mathrm{~g}$, assessed for molt stage (the molt score was recorded) and released from the aviary at dawn. The body temperatures were registered after measuring the MR using a thermistor taped inside the cloaca and connected to a remote readout device.

In a series of experiments, the respiratory quotient RQ was determined using a Haldene gas analyzer, designed on the successive absorption of the components of the gas mixture (carbon dioxide is absorbed by alkali and oxygen through pyrogallol), to measure the volume of residual gas. Air samples from the sealed chamber, in which the birds breathed for $15 \mathrm{~min}$, were collected into a special bag (Syringe A-7, $70 \mathrm{~mL}$, using a soft tip). The volume of breathed air was measured in a gas meter, and the samples were analyzed for the $\mathrm{O}_{2}$ and $\mathrm{CO}_{2}$ concentrations. A known volume of the gas sample was first treated with $\mathrm{KOH}$ solution. The $\mathrm{CO}_{2}$ concentration in the expired air was determined as the amount of $\mathrm{CO}_{2}$ uptake through $\mathrm{KOH}$ corresponding to a decrease in the original volume of the gas sample analyzed. The remaining gas was exposed to alkaline pyrogallate (pyrogallic acid in $\mathrm{KOH}$ ), which absorbs $\mathrm{O}_{2}$, to determine the concentration of oxygen in the expired air. Because the bird inhaled atmospheric air of a known composition (practically constant), determining the amount of $\mathrm{O}_{2}$ utilized and $\mathrm{CO}_{2}$ exhaled was a simple task. Based on these values, the RQ was calculated using the following formula: $\mathrm{RQ}=\mathrm{Vol}-$ ume of $\mathrm{CO}_{2}$ exhaled/Volume of $\mathrm{O}_{2}$ utilized. Benadé et al. [28] conducted experiments, in which the oxygen and carbon dioxide content and the RQ values obtained from the expired air samples using the Haldane technique, were compared with those obtained using paramagnetic and infrared analysis. No significant bias was observed between the Haldane and paramagnetic analyses of oxygen content. Infrared analysis showed more consistent results for $\mathrm{CO}_{2}$ than those obtained using the Haldane apparatus. According to the calculated RQ values, the chemical and physical methods were nearly identical. Thus, physical methods, when properly used and frequently calibrated, are as accurate as the accepted standard chemical methods [28].

Thus, I measured the resting energy expenditure and respiratory quotient in passerine and non-passerine species of during the winter and summer. The measurements were obtained at different temperatures ranging from +5 to $+35^{\circ} \mathrm{C}$.

Using a third series of measurements, I determined the oxygen consumption and carbonic gas exhalation in birds using a FoxBox $\mathrm{C}$ flow-through respirometer (Sable Systems Inc.). Simultaneously the rate of air passage through the chamber, temperature in the chamber, and the concentration of carbonic gas and oxygen were recorded. The intensity of ventilation of the respirometer chamber (passage rate) was set within $600-850 \mathrm{~mL} /$ min. Air was continuously blown through the hermetic respiration chamber in which the bird was located. The rate of oxygen consumption and carbonic gas exhalation was calculated as the difference between the concentration of these gases at the output of the respiration chamber containing the bird and the output of a similar empty chamber, multiplied by the rate of air passage through the chamber. The concentration of carbonic gas and oxygen in the respiration chamber containing the bird and a similar empty chamber was successively measured for 24-30 and 6-10 $\mathrm{min}$, respectively. The readings were obtained 
once every $10 \mathrm{~s}$. Measurements were obtained at night in a darkened chamber at different ambient temperatures. The measurements were obtained at $1-2 \mathrm{~h}$ after the birds fell asleep and the chamber temperature stabilized. The respiratory quotient was determined during these experiments. The energy metabolism was continuously calculated based on the calculated values of the respiratory quotient at a given moment of time. This series of experiments were performed at the start of the experiment, and after 25 species were measured, the results concerning one of these species were published [29].

The values for oxygen consumption were obtained using an updated respirometer, and these values were corrected to standard pressure and temperature according to the equations of Depocas and Hart [30].

\section{The stoichiometric approach to calculation}

\section{of total evaporative water loss and relationship} between evaporative and non-evaporative heat loss

Simultaneous determination of the energy expenditure and mass loss in resting birds was used to estimate their energetic equivalent of body mass loss $(q)$. During the measurements of $q$, the birds were in the post-absorptive state, and because measurements were performed during the non-breeding, non-molting, non-migrating seasons of the year, no production (growth or reproduction) occurred during these measurements. The birds did not have drinking water, and they metabolized previously ingested food. I performed preliminary experiments to determine the time of a day (in 24-h cycle) when the loss of body mass of the bird was minimal and bird's rate of metabolism was constant. My data for both species were consistent with the results of previous experiments [3, $31-34]$. That is mass losses resulting from cloacal excretions and products of nitrogen metabolism remain very small 4 hours after feeding and they may be ignored. Therefore, the main variable affecting the $q$ value is the pulmonary and cutaneous evaporation of water. This interrelationship is expressed as follows:

$$
q=C_{\mathrm{s}} \cdot D_{\mathrm{W}} / D_{\mathrm{m}}
$$

where $C_{\mathrm{s}}$ is the energetic content $(\mathrm{kJ} / \mathrm{g})$ of the oxidized ingredient (fat $=39.7 \mathrm{~kJ} / \mathrm{g}$; carbohydrate $=17.6 \mathrm{~kJ} / \mathrm{g}$; protein $=18.4 \mathrm{~kJ} / \mathrm{g}$ ), $D_{\mathrm{W}}$ is the mass of food oxidized during energy metabolism (in further calculations $D_{\mathrm{W}}=1 \mathrm{~g}$ ), and $D_{\mathrm{m}}$ is the loss of body mass comprising the following components:

$$
\begin{aligned}
D_{\mathrm{m}}= & \left(C_{\mathrm{s}} \cdot W \cdot \% H_{\mathrm{e}}\right) /(2.42 \times 100) \\
& + \text { cloacae discharge }+D_{\left(\mathrm{CO}_{2}-\mathrm{O}_{2}\right)}
\end{aligned}
$$

where $C_{\mathrm{s}} \cdot W / 2.42 \times 100$ is the amount of water $(\mathrm{g})$ necessary for the evaporative removal $1 \%$ heat generated through the oxidation of $W$ g compound of known energetic content $\left(C_{\mathrm{s}}\right), \% H_{\mathrm{e}}$ is the evaporative heat loss expressed as a percentage of total heat produced during the oxidation of any amount of this compound in the organism, cloacae discharge is the loss of body mass as excreted urine and feces, and $\mathrm{D}\left(\mathrm{CO}_{2}-\mathrm{O}_{2}\right)$ is the difference in body mass gained from the oxygen consumed and the mass lost from the $\mathrm{CO}_{2}$ released.

The $q$ value, representing the energy equivalent of body mass lost, is associated with the level of respiratory evaporation. For example, at higher ambient temperatures, evaporation rapidly increases relative to the metabolic rate observed when birds pant. The relationship between the energy equivalent and the level of evaporation is readily quantified $[25,26,31,32,35]$.

During the oxidation of $1 \mathrm{~g}$ of fat, $39.7 \mathrm{~kJ}$ of heat is produced, and the mass of oxygen consumed is $0.07 \mathrm{~g}$ greater than the mass of carbon dioxide released, yielding $1.07 \mathrm{~g}$ of metabolic (oxidation) water.

During the oxidation of $1 \mathrm{~g}$ of fat, the mass of oxygen consumed is $0.07 \mathrm{~g}$ greater than the mass of carbon dioxide released, yielding $1.07 \mathrm{~g}$ of metabolic (oxidation) water, and $39.7 \mathrm{~kJ}$ of heat is also produced. Thus, in the absence of evaporation, the bird gains $0.07 \mathrm{~g}$ of body mass for each gram of fat oxidized as a result of metabolic water. The heat of water vaporization is $2.42 \mathrm{~kJ} / \mathrm{g}$. When a portion of the heat produced during metabolism is lost via evaporation, the loss of body mass $\left(D_{\mathrm{m}}\right)$ per $1 \mathrm{~g}$ of the oxidized substrate (fat) resulting from evaporative heat loss $\left(H_{\mathrm{e}}\right)$ is:

$$
D_{\mathrm{m}}=39.7 \times \% H_{\mathrm{e}} /(2.42 \times 100)-0.07
$$

where $\% H_{\mathrm{e}}$ is the percent of total heat produced lost through evaporation. Considering the constant addition of mass resulting from excess metabolic water, which, with respect to loss of body mass, is a negative value, $q$ is dependent on the proportion of body heat production lost via evaporation at rest during the oxidation of fat, determined as

$$
\begin{aligned}
q & =39.7 /(39.7 /(2.42 \times 100)) \times \% H_{\mathrm{e}}-0.07 \\
& =39.7 / 0.164 \times \% H_{\mathrm{e}}-0.07
\end{aligned}
$$

There are two unknown variables in this equation: $q$ and $\% H_{\mathrm{e}}$; however, $q$ is an experimentally determined value obtained at different ambient temperatures. Thus, $\% H_{\mathrm{e}}$ can be calculated as

$$
\% H_{\mathrm{e}}=(39.7 / q+0.07) / 0.164
$$

Upon the oxidation of $1 \mathrm{~g}$ of carbohydrate, $17.6 \mathrm{~kJ}$ of heat is released and $0.56 \mathrm{~g}$ of metabolic water is produced, and because the mass of released carbon dioxide is $0.44 \mathrm{~g}$ more than the mass of consumed oxygen, this variable is not associated with the loss of body mass through evaporation. Correspondingly, the dependence 
of body mass loss and $q$ on the level of evaporative heat loss during carbohydrate oxidation is represented as

$$
\begin{aligned}
& D_{\mathrm{m}}=(17.6 / 2.42 \times 100) \times \% H_{\mathrm{e}}+0.44 \\
& \quad=0.072 \times \% H_{\mathrm{e}}+0.44 \\
& q=17.6 / D_{\mathrm{m}}=17.6 /\left(0.072 \times \% H_{\mathrm{e}}+0.44\right)
\end{aligned}
$$

The oxidation of $1 \mathrm{~g}$ of protein yields $18.4 \mathrm{~kJ}$ of heat, $0.49 \mathrm{~g}$ of metabolic water and $0.47 \mathrm{~g}$ of nitrogen metabolism products. Because the weight of released $\mathrm{CO}_{2}$ is $0.04 \mathrm{~g}$ more than the mass of consumed oxygen and because nitrogen metabolism products are excreted during prolonged experiments, the loss of body mass at $\% H_{\mathrm{e}}=0$ is $0.47 \mathrm{~g}+0.04 \mathrm{~g}=0.51 \mathrm{~g}$ per $1 \mathrm{~g}$ of oxidized protein, determined as

$$
\begin{aligned}
& D_{\mathrm{m}}=(18.4 / 2.42 \times 100) \times \% H_{\mathrm{e}}+0.51 \\
& \quad=0.076 \times \% H_{\mathrm{e}}+0.51 \\
& q=18.4 / D_{\mathrm{m}}=18.4 /\left(0.076 \times \% H_{\mathrm{e}}+0.51\right)
\end{aligned}
$$

Equations (4), (5) and (6) can be transformed into an exponential form. For fat metabolism, Eq. (4) is represented as

$$
\begin{aligned}
& \% H_{\mathrm{e}}=238.3 q^{-0.98}, \text { where } q \text { is in } \mathrm{kJ} / \mathrm{g} \text {, or } \\
& \% H_{\mathrm{e}}=2.76 q^{-0.98,} \text {, where } q \text { is in } \mathrm{W} / \mathrm{g}
\end{aligned}
$$

Equation (7) facilitates the calculation of $\% H_{\mathrm{e}}$ for specific $q$ values for fat metabolism, determined during the winter.

Evaporative heat loss for any combination of oxidized compounds can be calculated using this method. Our early work [36-38], based on the change of the diurnal variations of body composition in finches and house sparrows during the annual cycle, suggested that during the summer period the ratio of oxidizable substrates at night was close to 0.7 for fat, 0.2 for carbohydrates and 0.1 for proteins. With such ratio of oxidizable substrates RQ must be equal to $0.7 \times 0.7+0.2 \times 1+0.1 \times 0.82=0.77$.

Oxidation of a molecule of Carbohydrate $6 \mathrm{O}_{2}$ $+\mathrm{C}_{6} \mathrm{H}_{12} \mathrm{O}_{6} \rightarrow 6 \mathrm{CO}_{2}+6 \mathrm{H}_{2} \mathrm{O}+38$ ATP RER $=\mathrm{V}_{\mathrm{CO}_{2}} / \mathrm{V}_{\mathrm{O}_{2}}$ $=6 \mathrm{CO}_{2} / 6 \mathrm{O}_{2}=1.0$. Oxidation of a molecule of Fatty Acid $23 \mathrm{O}_{2}+\mathrm{C}_{16} \mathrm{H}_{32} \mathrm{O}_{2} \rightarrow 16 \mathrm{CO}_{2}+16 \mathrm{H}_{2} \mathrm{O}+129$ ATP RER $=\mathrm{V}_{\mathrm{CO}_{2}} / \mathrm{V}_{\mathrm{O}_{2}}=16 \mathrm{CO}_{2} / 23 \mathrm{O}_{2}=0.7$. Oxidation of a molecule of albumin $63 \mathrm{CO}_{2}+38 \mathrm{H}_{2} \mathrm{O}+\mathrm{SO}_{3}+9$ $9 \mathrm{CO}\left(\mathrm{NH}_{2}\right)_{2}+36$ ATP RER $=\mathrm{V}_{\mathrm{CO}_{2}} / \mathrm{V}_{\mathrm{O}_{2}}=63 \mathrm{CO}_{2} / 77 \mathrm{O}_{2}$. Calculation of the RQ for the same ratio of molecules oxidized substrates gives $0.7\left(16 \mathrm{CO}_{2} / 23 \mathrm{O}_{2}\right)+0.2(6$ $\left.\mathrm{CO}_{2} / 6 \mathrm{O}_{2}\right)+0.1\left(63 \mathrm{CO}_{2} / 77 \mathrm{O}_{2}\right)=11.2 \mathrm{CO}_{2} / 16.1 \mathrm{O}_{2}$ $+1.2 \mathrm{CO}_{2} / 1.2 \mathrm{O}_{2}+6.3 \mathrm{CO}_{2} / 7.7 \mathrm{O}_{2}=18.7 \mathrm{CO}_{2} / 25.0$ $\mathrm{O}_{2}=0.748$. But $1 \mathrm{~g}$ of fat, carbohydrates or proteins contains different amounts of molecules. Substrates themselves are not made of pure glucose, albumin and different ratios of fatty acids, so the meanings are slightly different (0.77 and 0.748). Therefore, it is permissible to take the proportion of oxidized substrates equal to 0.7 for fat, 0.2 for carbohydrates and 0.1 for proteins for the summer period at night.

A combination of oxidized substrates in the bird species during the summer, including fats, carbohydrates and proteins at 0.7:0.1:0.2, respectively, was used. The total $q$ comprises $0.7 q$ for fats, $0.1 q$ for carbohydrates and $0.2 q$ for protein, represented as

$$
\begin{aligned}
q= & 0.7 \times 39.7 /\left(0.164 \times \% H_{\mathrm{e}}-0.07\right)+0.1 \\
& \times 17.6 /\left(0.072 \times \% H_{\mathrm{e}}+0.44\right) \\
& +0.2 \times 8.4 /\left(0.076 \times \% H_{\mathrm{e}}+0.51\right)
\end{aligned}
$$

For the exponential form, this equation is represented as

$$
\begin{aligned}
& \% H_{\mathrm{e}}=239.3 q^{-1.05}, \quad \text { where } q \text { is in } \mathrm{kJ} / \mathrm{g} \text {, or } \\
& \% H_{\mathrm{e}}=2.77 q^{-1.05}, \quad q \text { in } \mathrm{W} / \mathrm{g}
\end{aligned}
$$

The regressions (7) and (9) were fitted using the leastsquares method of linear regression.

Total evaporative water loss is represented as

$$
\mathrm{TEWL}=\left(\mathrm{MR} \times \% H_{\mathrm{e}} / 100\right) / 2.42
$$

where MR is the total heat produced at any $T_{\mathrm{A}}$, and $\% H_{\mathrm{e}}$ is the percent of total heat lost through evaporation at this $T_{\mathrm{A}}$.

Therefore, a definite correlation between the energy equivalent and level of evaporative heat loss for any ambient temperature was observed. Because there is also a specific level of heat production for any temperature, it was possible to calculate the heat dissipated through evaporation at any ambient temperature and the amount of water spent to dissipate that amount of heat, as the evaporative heat of $1 \mathrm{~g}$ of water is equal to $2.42 \mathrm{~kJ}$ [39].

The correlation of evaporative and non-evaporative heat loss was obtained as follows: starting with $q$, I calculated $\% H_{\mathrm{e}}$ for specific ambient temperatures from Eqs. (7) and (9), then $H_{\mathrm{e}}$ was calculated from the total level of heat loss at specific ambient temperatures $\left(0{ }^{\circ} \mathrm{C}\right.$ for SMR, $T_{\mathrm{lc}}$ for BMR, $T_{\mathrm{uc}}$ for BMR, $25^{\circ} \mathrm{C}$ for $\mathrm{SRM}_{25^{\circ}}$ ) as follows: $H_{\mathrm{e}}=\mathrm{SMR} \times \% H_{\mathrm{e}} / 100$ or $H_{\mathrm{e}}=\mathrm{BMR} \times \% H_{\mathrm{e}} / 100$ or $H_{\mathrm{e}}=\mathrm{SRM}_{25^{\circ}} \times \% H_{\mathrm{e}} / 100$. The evaporative water loss (TEWL, in $\mathrm{g} /$ day) was calculated from the following equation: TEWL $=H_{\mathrm{e}} / 2.42$. Deducting $H_{\mathrm{e}}$ from the total heat loss (SMR or BMR), heat loss through conduction, convection and radiation (or non-evaporative heat loss, $H_{\mathrm{s}}$ ) was as follows: $H_{\mathrm{s}}=\mathrm{SMR}-H_{\mathrm{e}}$ or $H_{\mathrm{s}}=\mathrm{BMR}-H_{\mathrm{e}}$.

The TEWL can be used to determine the nonevaporative thermal conductance in birds. The determination of non-evaporative heat loss facilitated the calculation of heat loss through conduction, convection and radiation 
via body insulation, i.e., nonevaporative thermal conductance at different ambient temperatures $\left(h_{\min }\right.$ and $\left.h_{\max }\right)$ was calculated according to the following equations.

Non-evaporative thermal conductance at low ambient temperatures (at $T_{\mathrm{A}}<T_{\mathrm{lc}}$, when the bird minimizes heat loss, $\left.h_{\min }\right)$ :

$$
\begin{aligned}
h_{\min }= & {\left[\left(\mathrm{SMR}-\mathrm{SMR} \times \% H_{\mathrm{e} 1} / 100\right)\right.} \\
& -\left(\mathrm{BMR}-\mathrm{BMR} \times \% H_{\mathrm{e} 2} / 100\right] /\left(T_{\mathrm{lc}}-T_{\mathrm{A}}\right)
\end{aligned}
$$

where SMR is the standard metabolic rate at $0{ }^{\circ} \mathrm{C}, \% H_{\mathrm{e} 1}$ is the percentage of evaporative heat loss at this temperature, $\mathrm{BMR}$ is basal metabolic rate, $\% \mathrm{H}_{\mathrm{e} 2}$ is the percentage of evaporative heat loss at $T_{\mathrm{A}}=T_{\mathrm{lc}}, T_{\mathrm{lc}}$ is the lower critical temperature and $T_{\mathrm{A}}$ is the ambient temperature at which $S M R$ is measured (in this case $0{ }^{\circ} \mathrm{C}$ ).

Non-evaporative thermal conductance at high ambient temperatures (at $T_{\mathrm{A}}=T_{\mathrm{uc}}$, when the bird "undresses itself" to maximize heat loss, $\left.h_{\max }\right)$ :

$$
h_{\max }=\left(\mathrm{BMR}-\mathrm{BMR} \times \% H_{\mathrm{e} 3} / 100\right) /\left(T_{\mathrm{B}}-T_{\mathrm{uc}}\right)
$$

where $\% H_{\mathrm{e} 3}$ is the percentage of evaporative heat loss at $T_{\mathrm{uc}}, T_{\mathrm{uc}}$ is the upper critical temperature, and $T_{\mathrm{B}}$ is the body temperature.

Calculations and statistical processing of the results were performed with the Statgraphics program package. All data are expressed as mean \pm SD. Figures (including curve fits and correlation coefficients) were produced using the Harvard Graphic 3.0 software package. Linear curve fits are plotted in Figs. 2 and 3, whilst the lines

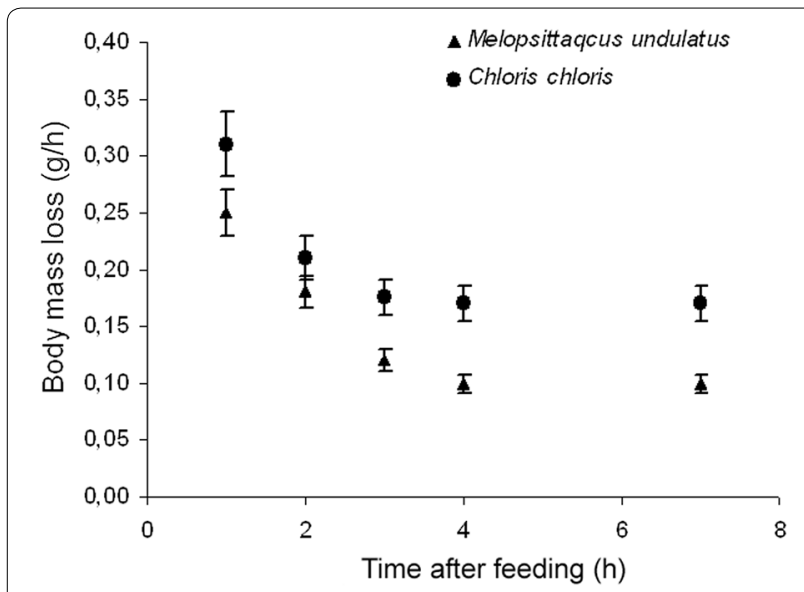

Fig. 2 Patterns of loss body mass. Body mass variations in 5 European greenfinches and 5 budgerigars after evening feed during the night, in summer. Each value is a mean for several measurements in 5 birds at given $T_{A}$, vertical lines \pm SD. The data show that all the birds became fasted for at least $3-4 \mathrm{~h}$ and were in post absorptive state during the measurements. It is evident that the birds lose their body mass with the equal rate during the measurement

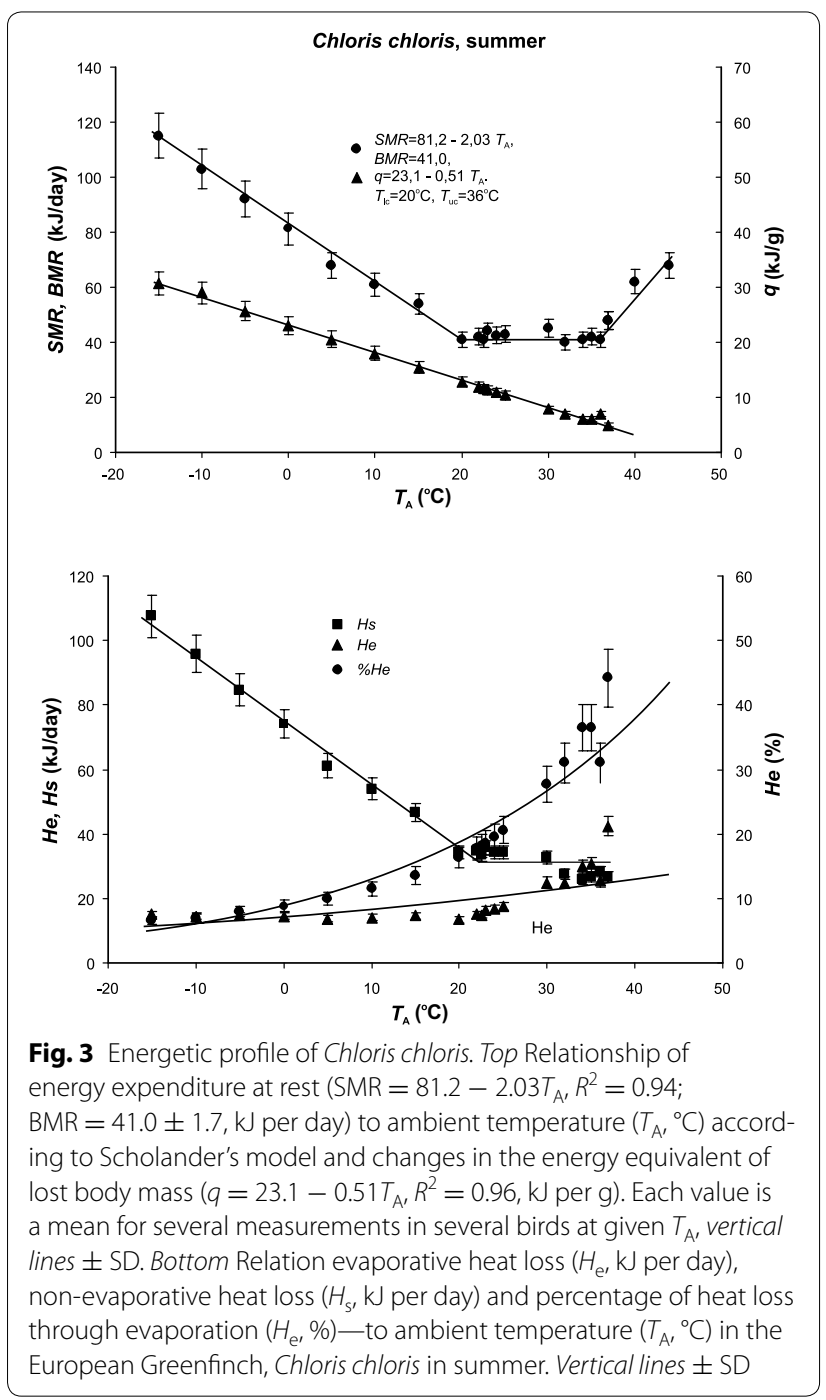

for $H_{\mathrm{e}}$ and $\% H_{\mathrm{e}}$ are polynomial curve fits. The relationships in this study were estimated by analysis of variance (ANOVA), and significance was determined by $t$ test, as appropriate. The following abbreviations associated with statistics are used in this paper: $n$, sample size; $p$, statistical significance; t-test for independent samples: Variables for Summer and Winter were treated as independent samples $r$, Pearson's linear correlation; SD, standard deviation.

\section{Results}

\section{Patterns of loss body mass}

The decrease of birds' body mass progressively decrease after the last feeding during the first 3-4 $\mathrm{h}$ and subsequently proceeded at a constant speed (Fig. 2). I considered that birds' alimentary canal became empty $4 \mathrm{~h}$ after the last feeding. 


\section{Result measurement of RQ}

RQ values in Melopsittacus undulatus and Chloris chloris at night in winter when ambient temperatures were in the range of $5-35{ }^{\circ} \mathrm{C}$ was in the range $0.69-0.75$ and on average equal to $0.72 \pm 0.02(n=14)$. These data indicate that lipids were the main source of energy expenditure in winter during night.

RQ values in Melopsittacus undulatus and Chloris chloris at night in summer when ambient temperatures were in the range of $5-35{ }^{\circ} \mathrm{C}$ was $0.74-0.82$ on average $0.77 \pm 0.08(n=24)$. Such RQs can be at any ratio of oxidizable substrates: lipids, carbohydrates and protein. Differences were not significant between Chloris chloris and Melopsittacus undulatus $(p>0.05)$ and were significant in both species for Summer and Winter data $(p<0.05)$.

\section{Data of metabolic rate, thermal conductance at lower} and upper temperatures energetic equivalent of the lost body mass, lower and upper critical temperatures, evaporative and non-evaporative heat loss and total evaporative water loss

The data for the heat loss at rest BMR, standard metabolic rate (SMR) and the other associated values measured $q$, non-evaporative heat loss $\left(H_{\mathrm{s}}\right)$, evaporative heat loss $\left(H_{\mathrm{e}}\right)$, and TEWL for two species during two seasons are summarized in Tables 1, 2, 3, 4. The data for the energetic profile for two species during the summer are presented in graphic form (Figs. 3, 4).

The changes of resting metabolic rate depend on $T_{\mathrm{A}}$ at night (Figs. 3, 4 top) and correspond to Scholander's model. Quantitatively, the metabolism or heat loss (SMR) is related to the $T_{\mathrm{A}}$ by the following direct equation:

$$
\mathrm{SMR}=h_{\mathrm{l}}\left(T_{\mathrm{B}}-T_{\mathrm{A}}\right)
$$

where $h_{1}$ is the coefficient of heat transfer or minimal thermal conductance.

The decrease in SMR ends when $T_{\mathrm{A}}=T_{\mathrm{lc}}$, gives a value of the basal metabolic rate (BMR). A further increase in $T_{\mathrm{A}}$ energy expenditure remains unchanged, whereas the birds pass from minimal wet thermal conductance $\left(h_{1}\right)$ to maximal $\left(h_{\mathrm{u}}\right)$, attained at $T_{\mathrm{A}}=T_{\mathrm{uc}}, h_{\mathrm{u}}=\mathrm{BMR} /\left(T_{\mathrm{B}}-T_{\mathrm{A}}\right)$, where $T_{\mathrm{A}}=T_{\mathrm{uc}}$.

Evaporative heat loss $\left(H_{\mathrm{e}}\right)$ dissipates $7.1-10.6 \%$ of the heat at $0{ }^{\circ} \mathrm{C}, 15.8-18.8 \%$ at $T_{\mathrm{lc}}$ and $45.2-63.2 \%$ at $T_{\mathrm{uc}}$. Based on the evaporative heat loss data, the non-evaporative heat loss at different ambient temperatures is then calculated. At low $T_{\mathrm{A}}$, the role of heat loss through evaporation is low, and nearly all the energy used in thermoregulation (SMR-BMR) is expended through conduction, convection and radiation. Evaporative heat loss increases significantly in the thermoneutral zone, even though the birds increase their thermal conductance. The determination of non-evaporative heat loss allows for calculation of heat loss through conduction, convection and radiation via body insulation. The non-evaporative thermal conductance at different ambient temperatures $\left(h_{\min }\right.$ and $\left.h_{\max }\right)$ was calculated (see Table 3 ).

Within the thermoneutral zone, the thermal conductance changes with changes of the temperature from minimum $\left(h_{\min }\right)$ to maximum at $T_{\mathrm{uc}}\left(h_{\max }\right)$. The $h_{\min }$ does not differ significantly from thermal conductance, including the evaporative heat loss of the entire bird at low $T_{\mathrm{A}}-h_{\mathrm{l}}$. The proportion of heat dissipated by water evaporation at $T_{\mathrm{A}}$ below $T_{\mathrm{lc}}$ is small and nearly the same at different $T_{\mathrm{A}}$ values below $T_{\mathrm{lc}}$. Evaporative heat loss decreases only at very low $T_{\mathrm{A}}\left(<-20{ }^{\circ} \mathrm{C}\right)$. At high $T_{\mathrm{A}}$, non-evaporative thermal conductance differs from wet thermal conductance $-h_{u}$, reflecting the increased role of evaporative heat loss.

\section{Discussion}

Comparison of predicted rates of evaporative water loss from allometric equations and data of this study

Comparison of predicted rates of evaporative water loss from allometric equations from literatures and this study is shown in Table 4. The analysis shows that determinations by stoichiometric approach of total evaporative water loss yielded the values, which fit

Table 1 Thermoregulation energetics at rest at night in Budgerigar and European Greenfinch in summer (S) and in winter (W)

\begin{tabular}{|c|c|c|c|c|c|c|c|c|c|c|}
\hline Species & $N$ & $M$ & Season & SMR & $H_{1}$ & $H_{\mathrm{u}}$ & $T_{\mathrm{lc}}$ & $T_{\mathrm{uc}}$ & BMR & $Q$ upon $T_{A}$ \\
\hline Melopsittacus undulatus & 18 & $25.2 \pm 0.6$ & Summer & $80.0 \pm 2.3$ & 2.00 & 8.65 & 27.0 & 39.0 & $26.0 \pm 0.7$ & $q=30.5-0.65 T_{\mathrm{A}}$ \\
\hline Melopsittacus undulatus & 18 & $33.6 \pm 0.5$ & Winter & $76.2 \pm 1.9$ & 1.83 & 8.13 & 26.0 & 38.5 & $28.5 \pm 1.2$ & $q=30.0-0.68 T_{\mathrm{A}}$ \\
\hline Chloris chloris & 17 & $28.2 \pm 0.4$ & Summer & $81.2 \pm 2.7$ & 2.03 & 6.84 & 20.0 & 36.0 & $41.0 \pm 1.3$ & $q=23.1-0.51 T_{\mathrm{A}}$ \\
\hline Chloris chloris & 17 & $29.0 \pm 0.3$ & Winter & $80.4 \pm 2.1$ & 2.15 & 8.03 & 16.0 & 36.0 & $48.1 \pm 0.9$ & $q=24.0-0.55 T_{\mathrm{A}}$ \\
\hline
\end{tabular}

Abbreviations: $n$ number of measured birds, $m$ average body mass $(\mathrm{g}), \mathrm{SMR}$ energy expenditure at rest at night at $T_{\mathrm{A}}=0{ }^{\circ} \mathrm{C}$ or standard metabolic rate at $T_{\mathrm{A}}=0{ }^{\circ} \mathrm{C}(\mathrm{kJ} /$ bird day), $h_{1}$ thermal conductance at rest (night) at low temperatures ( $\mathrm{kJ} /$ bird day $\left.{ }^{\circ} \mathrm{C}\right), h_{\mathrm{u}}$ thermal conductance at rest (night) at upper critical temperature $\left(h_{\mathrm{u}}=\mathrm{BMR} /\right.$ $\left(T_{\mathrm{B}}-T_{\mathrm{uc}}\right)\left(\mathrm{kJ} /\right.$ bird day $\left.{ }^{\circ} \mathrm{C}\right) T_{\mathrm{Ic}}$, lower critical temperature $\left({ }^{\circ} \mathrm{C}\right), T_{\mathrm{uc}}$ upper critical temperature $\left({ }^{\circ} \mathrm{C}\right), T_{\mathrm{B}}$ body temperature, ${ }^{\circ} \mathrm{C}, B M R$ basal metabolic rate $(\mathrm{kJ} /$ bird day), $q$ energetic equivalent of loss body mass at rest $(\mathrm{kJ} / \mathrm{g})$

Differences are significant $(p<0.05)$ between the summer and winter values in Chloris chloris and are not significant between summer and winter values in Melopsittacus undulatus 


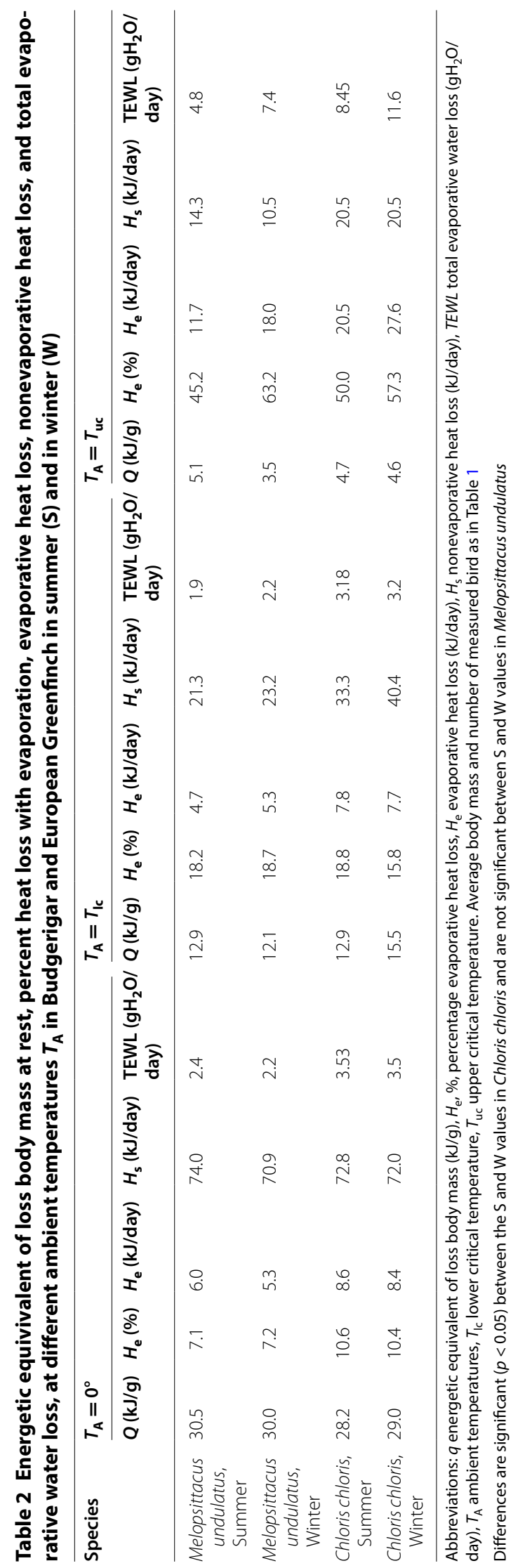


Table 3 Different thermal conductance at rest with evaporation and non-evaporation in Budgerigar and European Greenfinch in summer (S) and in winter (W)

\begin{tabular}{|c|c|c|c|c|c|c|c|}
\hline Species & Season & $H_{1}$ & $H_{\mathbf{u}}$ & $H_{\mathrm{u}} / h_{\mathrm{I}}$ & $H_{\min }$ & $H_{\max }$ & $H_{\max } / h_{\min }$ \\
\hline Melopsittacus undulatus & Summer & 2.00 & 8.65 & 4.325 & 1.80 & 7.0 & 3.9 \\
\hline Melopsittacus undulatus & Winter & 1.83 & 8.13 & 4.44 & 1.73 & 7.0 & 4.1 \\
\hline Chloris chloris & Summer & 2.03 & 6.84 & 3.4 & 1.81 & 7.0 & 3.9 \\
\hline Chloris chloris & Winter & 2.15 & 8.03 & 3.7 & 1.80 & 6.8 & 3.8 \\
\hline
\end{tabular}

Abbreviations: $h_{1}$ thermal conductance at rest (night) at low temperatures (kJ/bird day $\left.{ }^{\circ} \mathrm{C}\right), h_{\mathrm{u}}$ thermal conductance at rest (night) at upper critical temperature $\left(h_{\mathrm{u}}=\mathrm{BMR} /\left(T_{\mathrm{B}}-T_{\mathrm{uc}}\right)\left(\mathrm{kJ} /\right.\right.$ bird day $\left.{ }^{\circ} \mathrm{C}\right), h_{\min }$ minimal nonevaporative thermal conductance at rest (night), $h_{\min }\left(\mathrm{SMR}-\mathrm{SMR} \times \% H_{\mathrm{e} 1} / 100\right)-\left(\mathrm{BMR}-\mathrm{BMR} \times \% H_{\mathrm{e} 2} / 100\right) /$ $\left(T_{\mathrm{lc}}-T_{\mathrm{A}}\right)(\mathrm{kJ} / \mathrm{bird}$ day $\mathrm{C})$, where $\mathrm{SMR}$ is standard metabolism at $0{ }^{\circ} \mathrm{C}, \% \mathrm{H}_{\mathrm{e} 1}$ is the percentage of evaporative heat loss at this temperature, $\mathrm{BMR}$ is basal metabolism, $\% \mathrm{H}_{\mathrm{e} 2}$ is the percentage of evaporative heat loss at $T_{\mathrm{A}}=T_{\mathrm{lc}}, T_{\mathrm{lc}}$ is the lower critical temperature and $T_{\mathrm{A}}$ is the ambient temperature at which SMR is measured (in this case $\left.0{ }^{\circ} \mathrm{C}\right) ; h_{\text {max }}$ maximal nonevaporative thermal conductance at rest (night), $h_{\max }=\left(\mathrm{BMR}-\mathrm{BMR} \times \% H_{\mathrm{e} 3} / 100\right) /\left(T_{\mathrm{B}}-T_{\mathrm{uc}}\right),\left(\mathrm{kJ} / \mathrm{bird}\right.$ day $\left.{ }^{\circ} \mathrm{C}\right)$, where $\% H_{\mathrm{e} 3}$ is the percentage of evaporative heat loss at $T_{\mathrm{uc}}, T_{\mathrm{uc}}$ is the upper critical temperature, $T_{\mathrm{B}}$ is body temperature. Average body mass and number of measured bird as in Table 1 Differences are not significant $(p>0.05)$ between the summer and winter values in Chloris chloris and in Melopsittacus undulatus

Table 4 Comparison of predicted rates of evaporative water loss from allometric literature equations and data of this study

\begin{tabular}{|c|c|c|c|c|c|c|c|c|c|}
\hline \multirow[t]{2}{*}{ Species } & \multirow[t]{2}{*}{$m$} & \multirow[t]{2}{*}{ Season } & \multicolumn{7}{|c|}{ TEWL at $T_{A}=25^{\circ} \mathrm{C}$ according to } \\
\hline & & & $\begin{array}{l}\text { This } \\
\text { study }\end{array}$ & $\begin{array}{l}\text { Crawford } \\
\text { and Lasiewski } \\
\text { [18] for Aves }\end{array}$ & $\begin{array}{l}\text { Williams } \\
{[19]} \\
\text { for Aves }\end{array}$ & $\begin{array}{l}\text { Williams [19] } \\
\text { for Aves, } \\
\text { from mesic } \\
\text { areas }\end{array}$ & $\begin{array}{l}\text { Williams [19] } \\
\text { for Aves, } \\
\text { from arid } \\
\text { areas }\end{array}$ & $\begin{array}{l}\text { Williams [19] } \\
\text { for Passerines } \\
\text { from mesic } \\
\text { areas }\end{array}$ & $\begin{array}{l}\text { Williams } \\
{[19]} \\
\text { for Aves }\end{array}$ \\
\hline $\begin{array}{c}\text { Melopsittacus } \\
\text { undulatus }\end{array}$ & 29.4 & Summer, Winter & 2.05 & 3.13 & 2.97 & & 2.22 & & 2.16 \\
\hline Chloris chloris & 28.6 & Summer Winter & 3.2 & 3.07 & 2.91 & 3.35 & & 2.96 & 2.14 \\
\hline
\end{tabular}

Abbreviations: $m$ average body mass (g), TEWL total evaporative water loss ( $\mathrm{gH}_{2} \mathrm{O} /$ day), Crawford and Lasiewski [18]: Aves: TEWL $=0.432 m^{0.585}$; Williams [19]: Aves $\mathrm{TEWL}=0.300 \mathrm{~m}^{0.678}$; Aves, from mesic areas TEWL $=0.365 \mathrm{~m}^{0.661} ;$ Aves, from arid areas, TEWL $=0.176 \mathrm{~m}^{0.750} ;$ Passerines from mesic areas TEWL $=0.670 \mathrm{~m}^{0.443} ;$ Aves, TEWL $=0.15 m^{0.789}$

into the confidence intervals of all equations from literatures. For the three equations (i.e. the Crawford and Lasiewski equation, the Williams equation based on allometric analysis, and the Williams equation generated from phylogenetically independent contrasts), the Crawford and Lasiewski equation yields the highest predictions of TEWL for Melopsittacus undulatus (Table 4).

I propose the new theoretical conception of stoichiometric approach in determining total evaporative water loss. Simultaneously I use the metabolic rate (oxygen consumption) of the bird at different $T_{\mathrm{A}}$ for determination the ration between evaporative and non-evaporative heat loss. The based assumptions remains the same as Lasiewski et al. [15] ones, but include now the energy expenditure in birds. As it was shown above, stoichiometric approach provides adequate data of TEWL. A major advantage of this method for determining TEWL is that condensation or freezing of water vapor does not affect measurement accuracy at low ambient temperatures, as it is in the case of measurements of humidity, dew point, or water vapor pressure.

\section{The relationship between evaporative} and non-evaporative heat loss and the bird ability to change heat loss

A bird can either change its heat generation at the same ambient temperature or retain heat generation at a constant level during changes in the ambient temperature $[4,40,41]$ and others). Recently, I have shown that heat loss by thermal conductance $\left(h_{\min }\right.$ and $\left.h_{\max }\right)$ depends on $T_{\mathrm{A}}$ and is theoretically equal to zero at $T_{\mathrm{A}}=T_{\mathrm{B}}[34,42$, 43]. In these studies, I suggested an experimental model that represents changes in the main endothermic animal energy parameters, which are dependent on $T_{\mathrm{A}}[34]$, Fig. 5).

The primary components of energy metabolism are minimal and maximal heat loss. Minimal and maximal heat losses consist of heat loss through conduction, convection, radiation, and evaporation. Because of the estimation of evaporative heat loss, the non-evaporative heat loss at different ambient temperatures may be obtained because the non-evaporative heat loss is equal to the total heat loss minus the evaporative heat loss. Minimal $\left(Q_{\min }\right)$ and maximal $\left(Q_{\max }\right)$ non-evaporative heat loss 

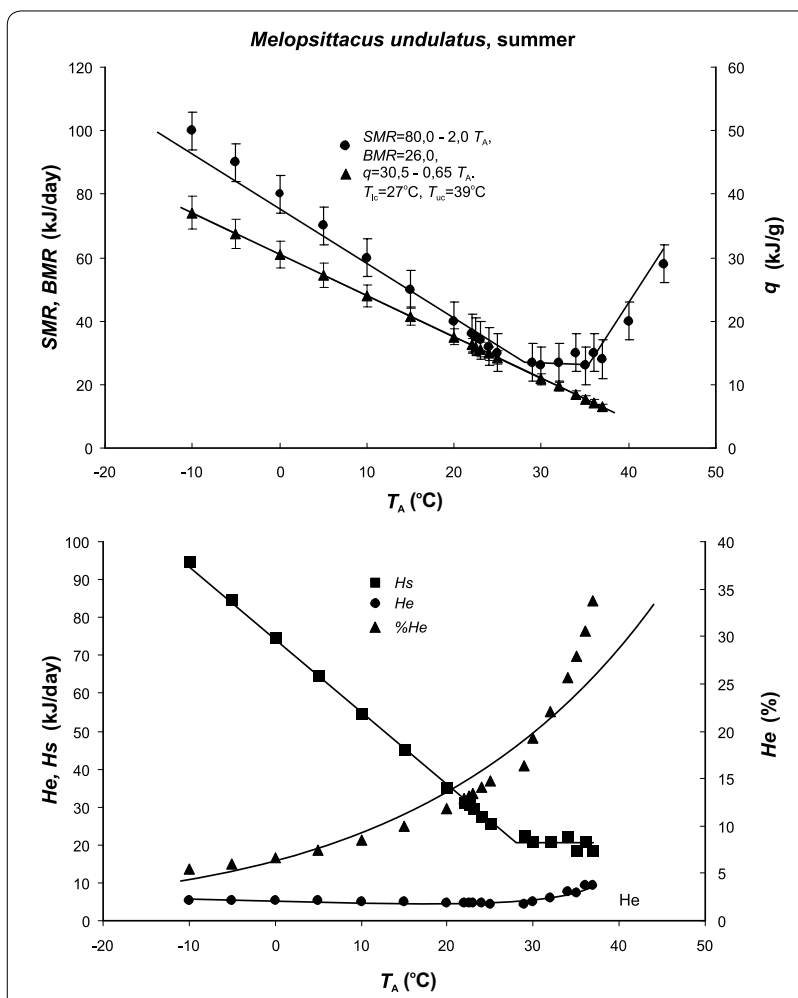

Fig. 4 Energetic profile of Melopsittacus undulatus. Top Relationship of energy expenditure at rest $\left(S M R=80.0-2.0 T_{A^{\prime}} R^{2}=0.96\right.$; $\mathrm{BMR}=26.0 \pm 0.7, \mathrm{~kJ}$ per day) to ambient temperature $\left(T_{\mathrm{A}^{\prime}}{ }^{\circ} \mathrm{C}\right)$ according to Scholander's model and changes in the energy equivalent of lost body mass $\left(q=30.5-0.65 T_{A^{\prime}} R^{2}=0.93, \mathrm{~kJ}\right.$ per $\left.\mathrm{g}\right)$. Each value is a mean for several measurements in several birds at given $T_{A^{\prime}}$ vertical lines \pm SD. Bottom. Relation evaporative heat loss $\left(H_{e^{\prime}} \mathrm{kJ}\right.$ per day), non-evaporative heat loss $\left(H_{s^{\prime}} \mathrm{kJ}\right.$ per day) and percentage of heat loss through evaporation $\left(H_{e^{\prime}} \%\right.$ ) - to ambient temperature $\left(T_{A}{ }^{\circ} \mathrm{C}\right)$ in Budgerigar, Melopsittacus undulatus in summer

are products of $h_{\min }$ or $h_{\max }$, respectively, and of the difference between the body temperature and the ambient temperature. Therefore, the minimal $\left(Q_{\min }\right)$ and the maximal $\left(Q_{\max }\right)$ heat losses are described by the following equations:

$$
\begin{aligned}
& Q_{\min }=h_{\min }\left(T_{\mathrm{B}}-T_{\mathrm{A}}\right) \\
& Q_{\max }=h_{\max }\left(T_{\mathrm{B}}-T_{\mathrm{A}}\right),
\end{aligned}
$$

where $Q_{\max }$ depends on the ambient temperature similar to $Q_{\min }$. The maximal and minimal non-evaporative heat loss $\left(Q_{\min }\right.$ and $\left.Q_{\max }\right)$ depend on $T_{\mathrm{A}}$ and are theoretically equal to zero at $T_{\mathrm{A}}=T_{\mathrm{B}}$, and both $Q_{\text {min }}=h_{\text {min }}\left(T_{\mathrm{B}}-T_{\mathrm{A}}\right) \approx \mathrm{SMR}$ and $Q_{\max }=h_{\max }\left(T_{\mathrm{B}}-T_{\mathrm{A}}\right) \approx$ MPE (maximal existence metabolic rate or maximal consumption of energy from food) exactly follow Newton's law in Scholander's interpretation. This explains many different components of endotherm energetics. Between these two heat losses converging at $T_{\mathrm{A}}=T_{\mathrm{B}}$, there is an area in which animals can function for long periods ( $M T$-metabolic temperature area). Respiratory heat loss widens this range towards high $T_{\mathrm{A}}$ (shown hatched in the figure); however, existence at these ambient temperatures is possible only at a high level of water evaporation and, consequently, at its compensation. The measurement data show that there are no differences in the mean non-evaporative thermal conductance between passerine and non-passerine species, both at maximal $\left(h_{\text {min }}\right)$ and at minimal $\left(h_{\max }\right)$ insulation. For 26 species of passerine and 16 non-passerine, I showed that $h_{\max }$ is approximately four times higher than $h_{\min }$. In both groups, $h_{\max }$ and $h_{\text {min }}$ change with changes in body mass in a similar manner, and the slopes of the regression lines at $h_{\min }$ and $h_{\max }$ are identical [34]. This observation indicates that birds are capable of dissipating different amounts of heat simultaneously without intensifying evaporative heat loss, and this amount may differ four-fold. The following equation:

$$
h_{\max }=4 h_{\min }
$$

is true. Minimal non-evaporative thermal conductance $\left(h_{\min }\right)$ essentially corresponds with wet thermal conductance measured by metabolic increase under cold load [5, $7,34,44-47]$ and exactly corresponds to the thermal conductance that is measured by the rate of cooling in bird carcasses [2]. The measurements of Herreid and Kessel [2] on skinned bird carcasses showed that the thermal conductance in these birds increases four-fold compared to intact carcasses as follows:

$$
\begin{aligned}
h_{\max }= & \left.0.608 m^{0.52} \text { (against } h_{\min }=0.146 m^{0.54}\right) \\
& \left(\text { units : } h_{\max } \text { and } h_{\min }, \text { Watt per }{ }^{\circ} \mathrm{C} ; m, \mathrm{~kg}\right)
\end{aligned}
$$

Notably, the two techniques for the estimation of $h_{\max }$ (Herreid and Kessel and my own) yielded similar results. However, the reason why the rate of cooling in a skinned bird carcass is four times higher than an intact carcass is because the feathery insulation reduces convective, radiant and evaporative losses from the skin because the feather-air interface temperature is much closer to the environmental conditions than it would be if the bare skin were exposed to those same environments. The mass of the torso is part of the thermal capacitance in a transient and its skin temperature is influenced by the external environment which, in the case of feathers being present, means that it cannot cool nearly as quickly because it cannot dissipate the heat as quickly to the environment.

The ability to alter heat loss without changing the level of heat production is proportional to the expression $h_{\mathrm{u}} / h_{\mathrm{l}}$, which, when the dependencies of $h_{\mathrm{u}}$ and $h_{1}$ on $m$ are substituted, produces the following relationships: 


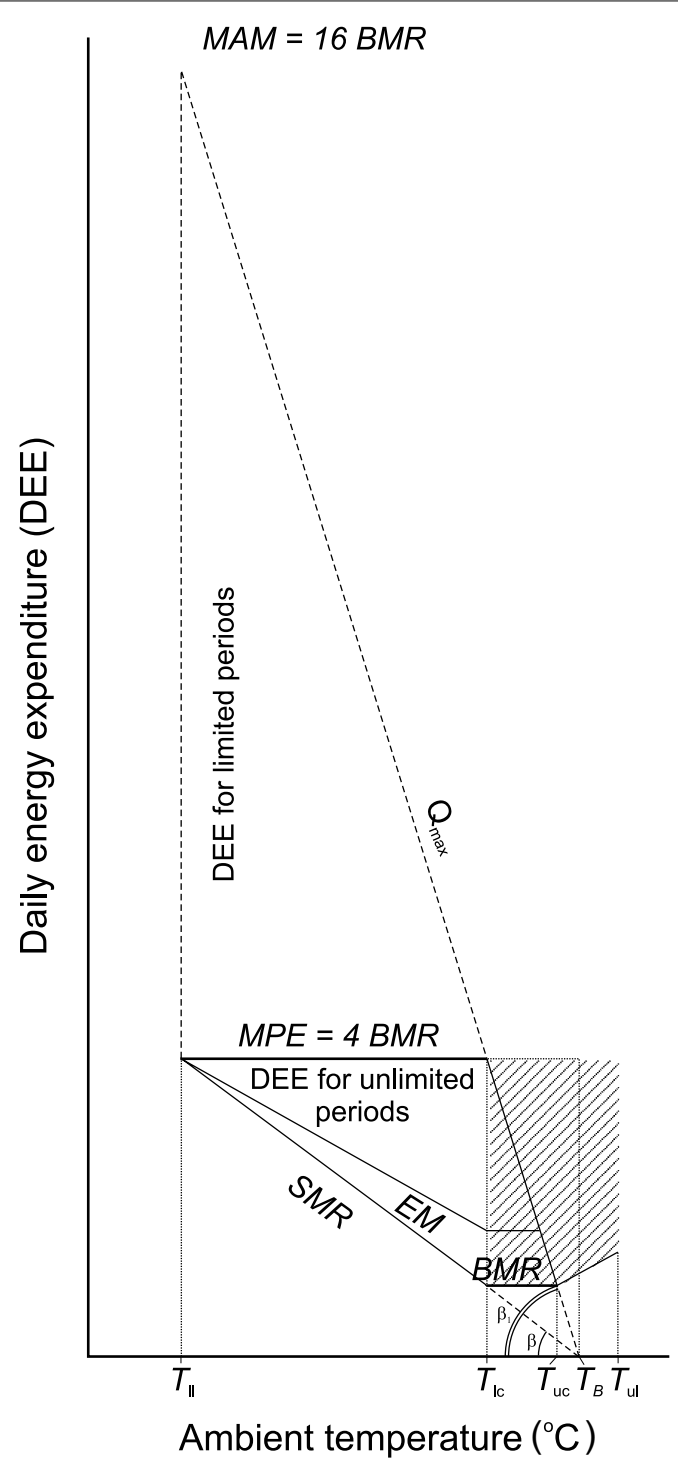

Fig. 5 Model of daily energy expenditure in an endothermic animal for an unlimited period from [34]. Daily energy expenditure (DEE) is based on experimentally determined dependencies of energy parameters on ambient temperature $\left(T_{A^{\prime}}{ }^{\circ} \mathrm{C}\right)$ : DEE $=h_{\min }(1-a \alpha)$ $\left(T_{B}-T_{A}\right)+a B M R$, where DEE is the daily energy expenditure at any activity level (a) and ambient temperature; $h_{\text {min, }}$ the minimum degree of change in nonevaporative heat dissipation (thermal conductance) at rest $h_{\min }=\mathrm{BMR}_{\mathrm{S}} / T_{\mathrm{B}}-T_{\mathrm{lc}} ; h_{\text {max }}$ the maximum degree of change in nonevaporative heat dissipation (thermal conductance) at rest $h_{\max }=B M R_{s} / T_{B}-T_{\text {uci }} h_{\max }=4 h_{\min } ; \alpha=1 / 4$, the coefficient of efficiency in converting metabolic into mechanical power (i.e., into work output); $T_{B}$, the body temperature $\left(40^{\circ} \mathrm{C}\right.$ in birds); BMR, the basal metabolic rate; $T_{I^{\prime}}$ the lower critical temperature; $T_{\mathrm{UC}}$, the upper critical temperature; $T_{\|}$, the lower limit of species temperature tolerance; $Q_{\min }=S M R=h_{\min }\left(T_{B}-T_{A}\right)$, the minimum heat dissipation or standard metabolic rate; $Q_{\max }=h_{\max }\left(T_{B}-T_{A}\right)$, the maximum heat dissipation; $\mathrm{EM}=h_{\mathrm{EM}}\left(T_{\mathrm{B}}-T_{\mathrm{A}}\right)+\mathrm{BMR}$, the existence metabolism; $a$, the activity level (at $a=0, \mathrm{DEE}=\mathrm{SMR}$; at $a=1, \mathrm{DEE}=\mathrm{EM})$; and $\mathrm{MPE}=h_{\max }\left(T_{\mathrm{B}}-T_{\mathrm{l}}\right)=4 \mathrm{BMR}$, the maximum potential existence metabolism. MAM is the maximum aerobic metabolism. The hatched zone corresponds to the evaporative heat dissipation
Melopsittacus undulatus:

$$
\begin{array}{ll}
\text { Winter } & h_{\mathrm{u}} / h_{1}=8.65 / 2.00=4.325 \\
\text { Summer } & h_{\mathrm{u}} / h_{\mathrm{l}}=8.13 / 1.83=4.44
\end{array}
$$

Chloris chloris:

$$
\begin{array}{ll}
\text { Winter } & h_{\mathrm{u}} / h_{1}=6.84 / 2.03=3.4 \\
\text { Summer } & h_{\mathrm{u}} / h_{1}=8.03 / 2.15=3.7
\end{array}
$$

The differences between the $\mathrm{S}$ and $\mathrm{W}$ values for both Passeriformes and non-Passeriformes are insignificant.

These results and the data for another 26 species of passerine and 16 non-passerine [34] indicates that passerine and non-passerine species do not differ significantly and do not show seasonal variations. Because $h_{\mathrm{u}}$ includes an essential share of heat loss through evaporation, it is important to determine the possible changes in heat loss that result only from a change in the nonevaporative thermal conductance that is proportional to $h_{\max } / h_{\min }$ as follows:

\section{Melopsittacus undulatus}

$$
\begin{aligned}
& \text { Winter } h_{\max } / h_{\min }=7.0 / 1.73=4.1 \approx 4 \\
& \text { Summer } h_{\max } / h_{\min }=7.0 / 1.8=3.9 \approx 4
\end{aligned}
$$

\section{Chloris chloris}

$$
\begin{aligned}
& \text { Winter } h_{\max } / h_{\min }=6.8 / 1.8=3.8 \approx 4 \\
& \text { Summer } h_{\max } / h_{\min }=7.0 / 1.8=3.9 \approx 4 .
\end{aligned}
$$

These data indicate that passerines and non-passerines species change their non-evaporative heat conductance the same number of times, which is approximately four, and that their abilities in this respect are similar. This result indicates the similarity of morphology and circulatory systems between these groups, the similarity of plumage properties and the mechanisms by which these groups change their thermal conductance. Notably, the minimal and maximal heat losses include heat loss through plumage, uncovered skin surfaces and vasomotor reactions.

The ratio $h_{\max } / h_{\min }$ primarily indicates the level of development of systems responsible for blood circulation and respiration. The increase in this parameter indicates the greater functional status of these systems, considerably facilitates any activity, and primarily enhances motility. However, the increase in this ratio causes decreased efficiency of the transformation of the metabolic rate to mechanical power. The latter is inversely proportionate to the ability to dissipate heat, the inverse ratio of $h_{\min } / h_{\max }$. Therefore, the ratio $h_{\max } / h_{\min }=4$ is characteristic for all endothermic animals and most likely results 
from a reasonable compromise between decreasing activity (BMR) and the minimal expedient value of efficiency of the transformation of the metabolic rate to mechanical power during activity. This is confirmed by an increase in efficiency with body size because large-bodied animals display lower levels of activity.

I propose that the maximal daily multiple value at BMR with relation to the daily energy expenditure (DEE) is determined experimentally with Eq. (12): $h_{\max }=4 h_{\min }$. According to equation number (1), birds, with no increase in evaporation at lower critical temperature, can dissipate 4BMR of heat regardless of their size, and their maximal metabolic power at this temperature may be equal to 4BMR per day for an unlimited period of time. This is corroborated by experimental data on the potential energy for both birds and mammals. The equations do not differ significantly from those of Calder for $H_{\max }$, Watt $=4.6 m^{0.65}(m, g)$ [48], and correspond to Saarela et al. [49] and the equation $M E_{\max }$, Watt $=2.8 \mathrm{~m}^{0.72}(\mathrm{~m}$, g) [50]. However, because no distinction was made in this study between passerines and non-passerines, they do differ in the exponent. This does not contradict the fact that metabolic power may considerably exceed this level during short time periods. For example, the daily energy expenditure in some species may reach 10-12 BMR over several days, but considerable time is required to replenish the energy stock.

As discussed above, the ability to change thermal conductance in endothermic animals is determined by the change of thermal conductance of the proper external tissues (plumage or wool) and also significantly affected by blood flow regulation for thermoregulation and locomotor activity. This observation indicates that the greater the $h_{\max } / h_{\min }$ relationship, the better the arrangement of the circulatory system, and this provides many advantages for any type of activity. The ratio $h_{\max } / h_{\min }=4$ is true for both passerine and non-passerine species and is important for understanding bird energetics [34].

\section{Conclusions}

Evaporation is a necessary attribute of the conservation of heat balance, but is largely derived from the metabolic rate, ambient temperature and relative humidity. Evaporation is caused by different gradients of water absorption at various temperatures and the difference between the density of saturating vapor and the actual density of vapor in the system from the surfaces of respiratory organs and skin. The experiments were performed at a relative normal humidity, and we did not use dried air, which stimulates evaporation.

The basal metabolic rate and non-evaporative thermal conductance are fundamental parameters of energetics and determine the level of physiological organization of an endothermic animal. Both parameters reflect the peculiarities of the circulatory and respiratory systems and the structure of the external covers. Non-evaporative thermal conductance is largely reflects the architecture of the circulatory system and vasomotor reactions. Therefore, the basal metabolic rate and non-evaporative thermal conductance are integrated parameters of the functioning of the systems associated with the assimilation of oxygen and maintenance of constant body temperature.

\section{Acknowledgements}

I am grateful to the researchers of the Department of Vertebrate Zoology and its head, L. P. Korzun, for the opportunity to perform research and for assistance and helpful discussions. I would like to thank A. I. Shilov for help with the drawings and, V. V. Gavrilov for assistance with the statistical calculations. I would also like to thank the Russian Foundation for Basic Research for longterm support of my research (grants \# 12-04-01288 and 16-04-00643). I thank T. B. Golubeva for support and patient and perceptive help with my studies.

\section{Compliance with ethical guidelines}

\section{Competing interests}

The author declares that he has no competing interests.

Received: 18 October 2014 Accepted: 15 September 2015 Published online: 06 October 2015

\section{References}

1. Arieli Y, Feinstein N, Raber P, Horowitz M, Marder J. Heat stress induces ultrastructural changes in cutaneous capillary wall of heat-acclimated Rock Pigeon. Am J Physiol. 1999;277:R967-74.

2. Herreid CFH II, Kessel B. Thermal conductance in birds and mammals. Comp Biochem Physiol. 1967;21:405-14.

3. Kendeigh SC, Dolnik VR, Gavrilov VM. Avian energetics. In: Pinowski J, Kendeigh SC, editors. Granivorous birds in ecosystems: their evolution, populations, energetics, adaptations, impact and control. Cambridge: Cambridge University Press; 1977. p. 127-378.

4. McNab BK. The physiological ecology of vertebrates: a view from energetics. Ithaca: Cornell University Press; 2002. p. 76.

5. Camps SGJA, Verhoef SPM, Westerterp KR. Weight loss, weight maintenance, and adaptive thermogenesis. Am J Clin Nutr. 2013;97:990-4.

6. Dawson WR. Evaporative losses of water by birds. Comp Biochem Physiol. 1982;71:495-509.

7. McCafferty DJ, Gilbert C, Thierry A-M, Currie J, Le Maho Y, Ancel A. Emperor penguin body surfaces cool below air temperature. Biol Lett. 2013;9:1192-6.

8. Schmidt-Nielsen K. How animals work. Cambridge: Cambridge University Press; 1972. p. 124

9. Smit B, Harding CT, Hockey PAR, McKechnie AE. Adaptive thermoregulation during summer in two populations of an arid-zone passerine. Ecology. 2013:94:1142-54.

10. Porter WP, Gates DM. Thermodynamic equilibria of animals with environment. Ecol Monogr. 1969;39:227-44.

11. Bernstein $\mathrm{MH}$. Cutaneous and respiratory evaporation in the painted quail, Excalfactoria chinensis, during ontogeny of thermoregulation. Comp Biochem Physiol. 1971;38:611-7.

12. DeNardo DF, Zubal TE, Hoffman TCM. Cloacal evaporative cooling: a previously undescribed means of increasing evaporative water loss at higher temperatures in a desert ectotherm, the Gila monster Heloderma suspectum. J Exp Biol. 2004;207:945-53.

13. Hoffman TCM, Walsberg GE, DeNardo DF. Cloacal evaporation: an important and previously undescribed mechanism for avian thermoregulation. J Exp Biol. 2007;210:741-9. 
14. Lasiewski RC, Acosta AL, Bernstein MH. Evaporative water loss in birds. I. Characteristics of the open flow method of determination and their relation to estimates of thermoregulatory ability. Comp Biochem Physiol. 1966;19:445-57.

15. Lasiewski RC, Acosta AL, Bernstein MH. Evaporative water loss in birds. II.-A modified method for determination by direct weighing. Comp Biochem Physiol. 1966;19:459-70.

16. Muñoz-Garcia A, Williams JB. Cutaneous water loss and lipids of the stratum corneum in house sparrows Passer domesticus from arid and mesic environments. J Exp Biol. 2005;208:3689-700.

17. Tieleman $\mathrm{Bl}$, Williams JB. Cutaneous and respiratory water loss in larks from arid and mesic environments. Physiol Biochem Zool. 2002;75:590-9.

18. Crawford ECJR, Lasiewski RC. Oxygen consumption and respiratory evaporation of the Emu and Rhea. Condor. 1968;70:333-9.

19. Williams JB. A phylogenetic perspective of evaporative water loss in birds. Auk. 1996;113:457-72.

20. Hutchinson JCD, Sykes AH. Physiological acclimatization of fowls to a hot humid environment. J Agric Sci. 1953;43:294-322.

21. Hutchinson JCD. A simple climatic chamber for physiological work with poultry. J Agric Sci. 1954;44:361-8.

22. Hutchinson JCD. Evaporative cooling in fowls. J Agric Sci. 1955;45:48-59.

23. Prosser CL (1991) Comparative animal physiology. Wiley-Liss Inc.; 4 edn; 1991. pp 592.

24. Górecki A. Kalabukhov-Skvortsov respirometer and resting metabolic rate measurement. In: Grodzinski W, Klekowski RZ, Duncan A, editors. Methods for Ecological Energetics. IBP Handbook N 24. Oxford: Blackwell Scientific; 1975. p. 309-13.

25. Gavrilov VM. Bioenergetics of large Passeriformes. 1. Metabolism of rest and energy of existence. Zool Zh. 1979;58:530-41.

26. Gavrilov VM. Bioenergetics of large Passeriformes. 2. Calorific value of weight, evaporative heat loss and dependence of bioenergetical parameters on body weight. Zool Zh. 1979;58:693-703.

27. Schmidt-Nielsen K. Animal physiology: adaptation and environment. Cambridge: Cambridge University Press; 1997.

28. Benadé AJS, Steydom NB, Walt WH. A comparison of physical and chemical methods for the determination of respiratory quotient. Internationale Zeitschrift für Angewandte Physiologie Einschließlich Arbeitsphysiologie. 1970;28:193-6.

29. Gavrilov VV, Veselovskaya EO, Gavrilov VM. Goretskaya MYa, Morgunova GV. Diurnal rhythms of locomotor activity, changes in body mass and fat reserves, standard metabolic rate, and respiratory quotient in the free-living Coal Tit (Parus ater) in the autumn-winter period. Biol Bull. 2013;40:678-83.

30. Depocas F, Hart JS. Use of the Pauling oxygen analyzer for measurement of animals in open circuit systems and in a short-lag, closed-circuit apparatus. J. App. Physiol. 1957;10:338-92.

31. Dolnik VR, Gavrilov VM. Caloric equivalent of body weight variations in chaffinch. In: Bykhovskii BE, editor. Bird migration: ecological and physiological factors. New York: Wiley; 1973. p. 273-87.

32. Gavrilov VM. Evaporative water loss in the class of birds: method of measurement and allometric dependencies at various ambient temperatures in passerine and nonpasserine birds. Doklady Biolog Sci. 1995;345:621-6.

33. Gavrilov VM. Energetics and avian behavior. In: Turpaev TM, editor. Soviet scientific reviews series, section F: physiology and general biology, vol 11, part 1. Amsterdam: Harwood Academic Publishers, Gordon and Breach PG; 1997. p. 225

34. Gavrilov VM. Ecological and scaling analysis of the energy expenditure of rest, activity, flight, and evaporative water loss in Passeriformes and non-Passeriformes in relation to seasonal migrations and to the occupation of boreal stations in high and moderate latitudes. Quart Rev Biol. 2014;89:107-50.
35. Dargoltz VG. The caloric equivalent of body weight changes of homoiothermal animals: relationship between oxidized substances and heat loss through evaporation. Zh Obshch Biol. 1973;34:887-98.

36. Dolnik VR, Gavrilov VM. A comparison of the seasonal and daily variations of bioenergetics, locomotor activities and major body composition in the sedentary house sparrow Passer d. domesticus L. and the migratory "Indian" sparrow P.d. bactrianus Zar. et Kudash. Ecol Polska. 1975;23:211-26.

37. Dolnik VR, Gavrilov VM. Bioenergetics of molt in the chaffinch Fringilla coelebs. Auk. 1979;2:253-64.

38. Gavrilov VM, Dolnik VR. Circannual cycles of the metabolism, behaviour and body mass composition in migratory and sedentary races of chaffinch and house sparrows. Ornithologia. 1976;12:178-99.

39. Garai J. Physical model for vaporization. Fluid Phase Equilib. 2009;283:89-97.

40. Taylor CR, Dmiel R, Fedak M, Schmidt-Nielsen K. Energetic cost of running and heat balance in a large bird, the rhea. Am J Physiol. 1971;221:597-601.

41. White CR, Phillips NF, Seymour RS. The scaling and temperature dependence of vertebrate metabolism. Biol Lett. 2006;2:125-7.

42. Gavrilov VM. Fundamental energetics of birds: 1 . The maximum ability of birds to change their thermal conductance and the efficiency of metabolic energy transformation into mechanical work. Biol Bull. 2012;39:569-78

43. Gavrilov VM. Fundamental avian energetics: 2 . The ability of birds to change heat loss and explanation of the mass exponent for basal metabolism in endothermic animals. Biol Bull. 2012;39:659-71.

44. Aschoff J. Thermal conductance in mammals and birds: its dependence on body size and circadian phase. Comp Biochem Physiol P. 1981;69:611-9.

45. Calder WA, King JR. Thermal and caloric relations of birds. In: Farner DS, King JR, editors. Avian Biology. New York: Academic Press; 1974. p. 259-413.

46. Gavrilov VM. Circadian changes of resting metabolism in birds. Ornithologia. 1981;16:42-50.

47. Lasiewski RC, Weathers WW, Berstein MH. Physiological responses of giant hummingbird, Patagona gigas. Comp Biochem Physiol. 1967;23:797-813.

48. Calder WA. Consequences of body size for avian energetics. In: Paynter RA, editor. avian energetics. Cambridge (Massachusetts): Nuttall Ornithological Club; 1974. p. 86-151.

49. Saarela S, Klapper B, Helmaier G. Thermogenic capacity of greenfinches and siskins in winter and summer. In: Bech C, Reinertsen R (eds) Physiology of Cold Adaptationin Birds. Plenum Publishing Corporation; 1989. pp 17-21.

50. Kirkwood JK. A limit to metabolisable energy intake in mammals and birds. Comp Biochem Physiol. 1983;75:1-3.

\section{Submit your next manuscript to BioMed Central and take full advantage of:}

- Convenient online submission

- Thorough peer review

- No space constraints or color figure charges

- Immediate publication on acceptance

- Inclusion in PubMed, CAS, Scopus and Google Scholar

- Research which is freely available for redistribution

Submit your manuscript at

www.biomedcentral.com/submit
C Biomed Central 